\title{
BEXIGA NEUROGENICA - UM PROBLEMA DE ENFERMAGEM
}

\author{
Eliseth Roncáglia de Carvalho* \\ Marlúcia N. Comarú * \\ Celina de Arruda Camargo*
}

RBEn/05

CaRValho, E.R., CAMARƯ, M.N. e CAMARgo, C.A. - Bexiga Neurogênica - Um problema de enfermagem. Rev. Bras. Enf.; DF, 29 : 40-44, 1976.

\section{INTRODUÇÃO}

Observando e sentindo a problemática apresentada pelos pacientes portadores de bexiga neurogênica e verificando ser a abordagem deste problema de interesse para a enfermagem, fizemos este relato, com o objetivo de descrever a assistência de enfermagem dispensada aos indivíduos com incontinência vesical, os recursos atuais existentes, as dificuldades encontradas e como foram superadas.

\section{CONSIDERAÇŐES GERAIS}

De acordo com BORRELLI (1), a "micção normal está sujeita a mecanismos voluntários e involuntários dependentes de centros nervosos que se escalonam desde o córtex cerebral até o plexo intrínseco da parede vesicular. Assim, qualquer lesão nervosa que interfira nesses mecanismos causará modificação no funcionamento da bexiga. Teremos então uma desfunção vesical de origem neurológica, denominada bexiga neurogênica". Desta maneira, um dos fatores que mais deprimem $o$ indivíduo portador de bexiga neurogênica é o fato de não poder controlar o seu fluxo urinário. A lesão nervosa de caráter permanente é de difícil aceitação por parte do paciente, que passa a isolar-se, fugindo do contato social.

Atitude anti-social, primitiva e regressiva, o fato de "molhar as roupas" passa a tomar proporçōes imensas para o indivíduo com incontinência urinária e se apresenta como um desafio para a enfermeira. O programa a ser desenvolvido depende em grande parte da sua capacidade de conhecer o paciente e a problemática que o envolve e da sua habilidade em proporcionar a assistência necessária. Este programa fundamenta-se basicamente no treinamento ou reeducação vesical.

De acordo com WIEBE (5) "treinamento vesical consiste no estabelecimento da habilidade de manter a capacidade vesical, esvaziando a bexiga completamente e adqurindo controle suficiente para evitar a incontinência".

Quanto mais cedo este treinamento for iniciado, mais satisfatórios serão os resultados obtidos.

* Enfermeiras da Divisão de Reabilitação Profissional de Vergueiro - Hospital das Clinicas da Faculdade de Medicina da Universidade de Sāo Paulo. 
Carvalho, e.R., Camarú, M.N. e CAMARGo, C.A. - Bexiga Neurogênica - Um problema de enfermagem. Rev. Bras. Enf.; DF, 29 : 40-44, 1976.

\section{ASSISTENCIA DE ENFERMAGEM}

Os objetivos principais da assistência de enfermagem a indivíduos portadores de bexiga neurogênica são:

- prevenção de infecções e cálculos vesicais;

- reeducação da função vesical;

- manutenção das roupas secas;

- manutenção da integridade da pele.

Inicialmente, após a constatação da lesão neurológica com comprometimento da bexiga, duas condutas médicas geralmente são seguidas - passagem de sonda vesical a intervalos regulares para proceder ao esvaziamento, ou colocação de sonda de demora, que inicialmente proporciona uma drenagem constante. Durante este periodo, que pode ser de três a quatro semanas, procura-se conhecer a situação funcional da bexiga, sua capacidade residual, a presença e a quantidade de resíduos urinários, a frequência de micçōes e as reaçōes do paciente em função das condições de sua bexiga.

Antes de se tentar qualquer método para controlar a incontinência vesical, é essencial a avaliação urológica sistemática das condiçōes da bexiga.

\section{Prevenção de infecções e cálculos vesicais}

Enquanto se processa a avaliação das condiçōes urinárias do paciente é importantíssimo prvenir as infecçōes e a formação de cálculos vesicais.

Isto pode ser conseguido através de periodicidade e técnica asséptica rigorosa na troca do cateter e de um programa de ingestão de grande quantidade de líquidos, que estimula o funcionamento renal, auxilia a eliminação de resíduos urinários, dificulta a formação de cálculos e a instalação de infecção.

A lavagem vesical periódica, já não é mais aconselhada, na tentativa de eliminação de mais uma fonte de contaminação, no entanto, alguns urologistas ainda indicam o seu uso.
Caso essas medidas preventivas não se-Jam suficientes para impedir a instalação de infecção, o médico recorre à antibioticoterapia, como parte do tratamento.

Desde que o paciente esteja livre deinfecção vesical pode-se tentar um programa de treinamento para esvaziamento periódico da bexiga.

\section{Fase de treinamento para reeducação vesical}

Elabora-se um programa de treinamento para o esvaziamento da bexiga de forma a ajudá-la a funcionar em ritmo. de frequência de eliminação tão próximo. ao normal quanto o possivel.

Para elaborar este programa, são necessárias algumas informaçōes relativas ao funcionamento anterior da bexiga, na. fase que antecedeu a instalação da lesão neurológica. Assim sendo, tenta-se conhecer quais eram os hábitos de eliminação: vesical do paciente, a relação de tempo que existia entre a ingestão de líquidos e a eliminação subseqüente e o tipo de líquido cujo periodo de eliminação era mais curto. Estas informaçōes nos ajudarão a elaborar um programa de trelnamento fundamentado no funcionamento habitual do organismo do paciente antes de ocorrer o problema vesicar e assim, não correr o risco de elaborar um programa rígido, tentando conseguir uma reeducação vesical isolada de outros' fatores que poderão interferir neste funcionamento.

O programa que passamos a relatar, parece rígido na sua apresentação descritiva, no entanto, todos os fatores acima apresentados devem ser levados em consideração na elaboração e execução do programa de cada paciente.

Primeiramente, a sonda de demora permanece fechada por meia hora, medindo-se o volume urinário e as características da urina eliminada. Progressivamente, a sonda vai sendo aberta a inter- 
CarValho, E.R., CAMarÚ, M.N. e CAMARGo, C.A. - Bexiga Neurogênica - Um problema de enfermagem. Rev. Bras. Enf.; DF, $29: 40-44,1976$.

valos maiores de uma hora, uma hora e meia, duas horas, até ser atingido o limite máximo de três horas ou o intervalo que o organismo do paciente permitir. Os intervalos de abertura da sonda devem permanecer fixos por 4 a 5 dias, evitando nuudanças bruscas no funcionamento vesical e facilitando a adaptação do organismo ao treinamento.

Todo o processo acima descrito, deve ser iniciado no princípio da semana, pela manhã e na medida do possível ser levado a efeito por uma mesma enfermeira. - $O$ registro dos procedimentos adotados é fundamental para que não ocorra interrupçōes que são prejudiciais, dificultam e retardam 0 alcance do nosso objetivo.

Neste periodo o paciente deve estar atento a qualquer sinal que indique a necessidade de esvaziamento vesical, não sendo necessariamente a sensação de desejo de urinar. Este sinal pode ser uma leve cefaléia, sensação de mal-estar, eriçamento de pêlos, sudorese, o importante é que o paciente reconheça qual o sinal emitido pelo seu organismo que precede - 0 ato da micção.

Os pacientes que após um período prolongado de treinamento nesta fase de abrir e fechar a sonda, não conseguem identificar previamente o sinal de plenitude vesical, devem provocar o esvaziamento da bexiga, aproximadamente quinze minutos antes do prazo previsto para a descarga vesical.

A micção, nestes casos pode ser conseguida através da manobra de Credé, ou seja, compressão do baixo ventre com as mãos espalmadas e flexão do tronco sobre as coxas. Nos casos de paraplegia, é importante verificar o equilibrio de tronco, que pode estar modificado e para evitar a projeção do corpo para frente, 0 paciente deve ser auxiliado nesta manobra. Este procedimento, no entanto, não deve ser utilizado constantemente pelo risco de infecção ascendente (ureteres e renais) e quando executado, a compres- são deve ser suave, evitando-se aumento perigoso da pressão intravesical.

O exercício de respiração abdominal também pode ser utilizado para estimular o esvaziamento vesical.

Este longo período de treinamento requer paciência da enfermeira e grande cooperação do paciente, pois o desânimo e o cansaço recaem sobre ele como um peso, necessitando de muito apoio e estímulo para enfrentar e superar esta fase que exige muito esforço.

O período para que se possa conhecer ainda que precariamente o funcionamento vesical, varia de paciente para paciente. através de registro cuidadoso de todos os fatos relacionados ao treinamento vesical programado que pode-se chegar a conhecer como ocorre o esvaziamento da bexiga do nosso paciente e desta forma, prepará-la para a fase seguinte que é a remoção da sonda e a continuação da eliminação vesical que foi conseguida pelo treinamento de forma a manter o ritmo obtido e evitar que venha a molhar as roupas.

Fase de treinamento para o autocuidado

Após a retirada da sonda, muitos aspectos deverão ser abordados com o paciente, tentando-se evitar complicaçōes como: infecçōes, cálculos e extravasamentos de urina.

Uma orientação clara, objetiva e enfocando a importância do cuidado que o paciente deve ter com seu corpo, é fundamental para a sua independência.

A ingestão de líquidos continua a ser bastante estimulada, numa média de $\mathbf{3 0 0 0}$ ml. diários, tentando-se prevenir as complicaçōes vesicais já referidas anteriormente. $O$ controle das características e do volume urinário, é importante. Qualquer alteração na cor, odor, volume ou quantidade de sedimentação, deve ser imediatamente notificada ao médico, ao mesmo tempo em que se inicia uma hidra- 
Carvalho, E.R., CAmarú, M.N. e CAMargo, C.A. - Bexiga Neurogênica - Um problema de enfermagem. Rev. Bras. Enf.; DF, 29 : 40-44, 1976.

tação oral intensa, visando maior estímulo para o funcionamento renal e vesical, auxiliando a eliminação de impureza.

O paciente pode ser orientado na utilização do método de Credé, já descrito anteriormente, antes de atividades dinâmicas que estimulariam o esvaziamento vesical e poderiam colocá-lo em situação socal delicada e inadequada.

A eliminação do conteúdo vesical deve ser feita, de pereferência, no vaso sanitário. Nos casos em que o paciente não reconhece $o$ sinal de plenitude vesical ou $o$ período é tão curto que não permite a sua eliminação no vaso sanitário ou "papagaio", é aconselhável usar um coletor que permita a descarga vesical sem molhar as roupas.

$O$ recipiente utilizado para a coleta da tirina drenada varia de acordo com 0 sexo.

Quando são pacientes do sexo feminino pode ser usado absorvente higiênico e calça plástica, sendo utilizado um creme hidratante e emoliente para se evitar problemas de maceração da vulva. A verificação constante das condiçōes de pele é essencial, assim como, as trocas freqüentes.

Para os pacientes do sexo masculino, o método mais comumente utilizado é uma adaptação feita com preservativo tipo Condon e uma extensão de borracha, presa a um recipiente onde é coletada a urina. Este reservatório está freqüentemente sujeito a transbordamento de urina e contaminação das roupas. Outro problema ligado a este tipo de coletor é o risco de se rasgar ou arrebentar o preservativo durante o fluxo urinário, além de ser completamente antiestético, por se tratar de recipiente de uso externo. Outra solução existente é o urinol de borracha, aparelho constituído de duas partes: uma bolsa que recobre o pênis, ligada a um recipiente que funciona como um reservatório de urina. Este aparelho é preso por alças elásticas à cintura, coxas e pernas do paciente, ficando invisivel por sob a roupa. Esta solução para a coleta da urina eliminada pode ser utillzada para os casos de incontinência urinária.

Estando o paciente em situação estática é aconselhável que ao pressentir o funcionamento vesical, ele distenda a perna e eleve o quadril para que no aparelho forme um canal contínuo e facilite o escoamento da urina pela ação da gravidade. Em situações dinâmicas, como por exemplo, exercícios fisioterápicos, os problemas de extravazamentos urinários podem ocorrer, pois qualquer fator que impeça o escoamento rápido da urina para o reservatório, faz com que haja refluxo para a bolsa que recobre o pênis e conseqüente transbordamento.

Existe, ainda, o problema de adaptação individual ao aparelho, ou seja, os modelos existentes são do tipo "standard" que nem sempre se adaptam convenientemente a todos os pacientes, sendo, algumas vezes, necessárias pequenas modificaçōes na estrutura do urinol de borracha.

A inadaptabilidade do urinol de borracha, muitas vezes, provoca lesões penianas extensas, sendo necessária a verificação contante das condiçōes da pele desta região.

A orientação sobre a lavagem diária do urinol de borracha é essencial, não só para prevenir infecções e odores desagradaveis como também para aumentar a durabilidade do aparelho.

Um cuidado extremamente importante, é a proteção da pele, evitando o contato direto das alças elásticas do urinol de borracha. Isto pode ser conseguido, protegendo-se a pele com tiras de tecido macio, bem passado e sem formação de pregas. Esta proteção da pele é essencial devido a falta de sensibilidade do paciente nestas áreas, tornando-as muito vulneráveis às ulceraçōes.

A verificação constante das condições 
CARVALHO, E.R., CAMARÚ, M.N. e CAMARGO, C.A. - Bexiga Neurogênica - Um problema de enfermagem. Rev. Bras Enf; DF, 29 : 40-44, 1976.

de pele, permite detectar alguns sinais de alteração como: edema, cor, temperatura, sensibilidade, escarificação, compressão e nestes casos, o médico deve ser informado.

O paciente precisa estar consciente da sua limitação na área de eliminação vesical e portanto, deve tornar-se responsável pela manutenção das condiçōes ideais de esvaziamento da bexiga, conseqüente da sua problemática vesical.

\section{COMENTARIOS E CONCLUSAO}

Podemos dizer que após inúmeras e variadas tentativas na solução deste difícil problema de indivíduos portadores de bexiga neurogênica, conseguimos atingir um estágio de relativa satisfação. Através do treinamento, a reeducação vesical pôde ser conseguida e desta forma o indivíduo controla o fluxo urinário o que lhe permite uma apresentação social adequada.

Como todos os métodos citados possuem vantagens e desvantagens, tentamos associá-los, corrigindo as falhas existentes em alguns através dos outros. Nestas condiçōes, foi feita uma adaptação com preservativo no urinol de borracha, sendo que o preservativo, aderente ao pênis é ligado a uma extensão de borracha, com calibre inferior ao da conexão entre as partes superiores e inferior do urinol de borracha, permitindo a sua passagem por este orifício.

A parte superior do urinol de borracha é colocada sobre o preservativo e sua extensão desemboca na bolsa coletora de borracha, evitando hiatos que possam facilitar o transbordamento do fluxo urinário.

Antes de atividades físicas, é utilizado o método de Credé, como meio mais seguro para o esvaziamento da bexiga, conseguindo-se prolongar por um período maior a descarga vesical.

Até o momento, esta associação de métodos tem dado bons resultados por períodos prolongados, ocorrendo, esporadi- camente, problemas de extravazamento urinários ligados a descuido do paciente por posição inadequada durante a descarga vesical ou perfuração do preservativo.

Por toda problemática existente na assistência de enfermagem dispensada a indivíduos portadores de bexiga neurogênica, a participação ativa do paciente na tentativa de atingir um estágio de não molhar as roupas, mesmo em situações dinâmicas, é muito importante e deve ser bastante estimulada.

As decepçōes são grandes e cada frustração leva o paciente ao desânimo e ao desinteresse, cabendo à enfermeira estar sempre apresentando novas sugestōes, idéias e proporcionando novas tentativas. $\mathrm{E}$ foi através de tentativas e falhas, esperanças e desesperanças, interesses e desinteresse, ânimo e desânimo, que conseguimos atingir um estágio quase que ideal, com os pacientes em reabilitação.

Juntos labutamos, tentamos, desistimos, tentamos novamente, com o único objetivo de tornar o indivíduo portador de bexiga neurogênica com condiçōes de convívio social livre de inibiçōes, medo e ansiedade pelo funcionamento involuntário de sua bexiga!

\section{BIBLIOGRAFIA}

1. BORRELLI, M. - Pediatria Básica. Sarvier, São Paulo, 1968.

2. DAVIS, M.D. \& STRONG, G.H. Urological Nursing. W.B. Saunders Company Philadelphia, 1953.

3. GORDON, E.E. - Multiple Sclerosis application of rehabilitation techniques, National Multiple Sclerosis Society, New York, 1957.

4. KEUHNELIAN, J.G. \& SANDERS, U.E. Urologic Nursing. The Macmillan Company - Collier - Macmillan Limited. London, 1970.

5. WIEBE, A.M. - Orthopedics in Nursing. W.B. Saunders Company. Philadelphia and London, 1961.

6. WINTER, C.C. \& BARKER, M.R. Nursing care of patients with urologic diseases - The C.. V. Mosby Company. Saint Louis, 1972. 